\title{
Fracture Characteristics of The Laser Bonding Joint Between The Aluminum Alloy and The CFRTP With Preset Aluminum Alloy Sheet
}

Jiebang Luo

Nanjing University of Aeronautics and Astronautics

Hengchang Bu

Nanjing University of Aeronautics and Astronautics

Feiyun Wang

Nanjing University of Aeronautics and Astronautics

Xiaohong Zhan ( $\nabla$ xiaohongzhan_nuaa@126.com )

Nanjing University of Aeronautics and Astronautics

Min Yu

Nanjing University of Aeronautics and Astronautics

Dongtao Liu

Nanjing University of Aeronautics and Astronautics

\section{Research Article}

Keywords: aluminum alloy, CFRTP, laser joining, fracture characteristic, compression molding

Posted Date: July 1st, 2021

DOI: https://doi.org/10.21203/rs.3.rs-642108/v1

License: () (1) This work is licensed under a Creative Commons Attribution 4.0 International License. Read Full License

Version of Record: A version of this preprint was published at The International Journal of Advanced Manufacturing Technology on January 31st, 2022. See the published version at https://doi.org/10.1007/s00170-021-08572-4. 


\section{Abstract}

This paper presents a method to improve the laser joint strength between carbon fiber reinforced thermoplastic composite (CFRTP) and aluminum alloy. In this method, the aluminum alloy sheet is preset between the polyetheretherketone (PEEK) and carbon cloth, while the CFRTP with preset aluminum alloy sheet is attained by the compression molding method. The CFRTP with preset aluminum alloy sheet is connected to the aluminum alloy by laser heat source, and the maximum load of the joint can reach 4264 $\mathrm{N}$. Microstructure and fracture surface morphology of joint are observed and analyzed. The results indicate that the element diffusion between the preset aluminum alloy sheet and CFRTP shows more significant compared with the interface of aluminum alloy and CFRTP due to the effect of hot pressing. The fracture failure mode of the lap structure between aluminum alloy and CFRTP is mixed fracture with adhesion fracture as the main component. The fracture position of preset aluminum alloy sheet and aluminum alloy lap structure occurs near the weld seam fusion line, while the fracture behavior presents a ductile fracture. The joint bonding force is mainly attributed to the collective effect of two lap structures, during the stretching process, the interface between aluminum alloy and CFRTP first undergoes fracture, then preset aluminum alloy sheet undergoes plastic fracture failure.

\section{Introduction}

With the development of lightweight in aerospace, CFRTP has gradually become a significant choice for structural materials in aerospace on account of its high specific strength, good fatigue resistance, and superior corrosion resistance [1-4]. In addition, aluminum alloys are still vital structural materials for aerospace vehicles for a long time in the future owing to their excellent properties such as high strength, high electrical conductivity, great thermal conductivity, and excellent corrosion resistance. Therefore, the joining of aluminum alloy and CFRTP is inevitable in the field of aviation manufacturing, and the reliable joining of CFRTP and aluminum alloy has become a research hotspot $[5,6]$.

For the joining technology of CFRTP and aluminum alloy, currently, adhesive bonding and mechanical joining are utilized widely $[7,8]$. However, these two technologies have distinct shortcomings. For adhesive bonding, the strength of adhesive bonding joints is easily affected by the environment, and the curing time of the cement is long $[9,10]$; For mechanical joining, the use of rivets for riveting will increase the weight of the structure, which does not meet the requirements for lightweight in the aerospace [11]. Furthermore, rivets can damage the carbon fibers in the composite material during the drilling process, causing stress concentration, thereby reducing the strength of the joint. As a thermal joining, laser joining technology not only avoid the above shortcomings but also possesses the advantages of energy concentration, high efficiency, non-contact, easy to automatic production. It has broad research prospects for achieving the reliable joining of CFRTP and aluminum alloy [12, 13].

In recent years, numerous researches have been carried out on the laser joining of CFRTP and aluminum alloy. Roesner et al. [14] successfully achieved the joining of 304 stainless steel with nylon and glass fiber reinforced polyamide by using laser transmission welding and thermal conduction welding, respectively. 
Jung et al. [15-17] conducted laser heat conduction technology to achieve reliable joining between CFRTP and galvanized steel, stainless steel, and aluminum alloy, respectively. The influence of bubbles generated during the joining process on the joint was studied, and the formation mechanisms of the three joints were analyzed, respectively. Sheng et al. [18] promoted the strength of the joint between CFRTP and stainless steel by adjusting process parameters such as laser power and laser scanning speed. Zhang et al. [19] adopted the swing laser process, which can effectively reduce bubbles and refine the weld grains, increasing the tensile strength of the joint by $39 \%$. In order to improve the strength of the joining joint between CFRTP and aluminum alloy, pre-treatment before the laser joining process can be performed at the joining interface, such as surface micromachining, phosphating, and chromium plating. Huang et al. [20] employed pulsed laser to structure different textures on the surface of the titanium alloy and performed the laser joining the titanium alloy and CFRP. The results proved that the joint strength has been greatly improved. Lambiase et al. [21] also adopted a similar method to connect aluminummagnesium alloy and PEEK. The strength of the joint can reach $30 \mathrm{MPa}$, which is equivalent to $53 \%$ of the shear strength of PEEK. Zhang et al. [22] conducted the laser Surfi-Sculpt ${ }^{\circledR}$ technology to produce a protrusions structure on the metal surface. The author held the view that the mechanical interlocking effect of the structure of the protrusion is more excellent than the effect of microstructure, which is mainly due to the structure of the protrusion can produce stronger pinning effect. Moreover, the author employed acrylic acid to modify the surface of carbon fiber by ultraviolet light, and the strength of the laser joint between aluminum alloy and CFRTP was increased from $5 \mathrm{MPa}$ to $30 \mathrm{MPa}$ [23]. 6061 aluminum alloy was anodized to form a porous structure on the surface of the aluminum alloy, while the changed surface wettability resulted in the higher strength of the laser joint between the aluminum alloy and CFRTP [24].

At present, the strength of laser-joined CFRTP and metal joints has been significantly improved through various means, but the strength of the joints has not yet been able to meet the current aerospace service requirements. In order to further enhance the laser joint strength of CFRTP and aluminum alloy, a laser joining process of aluminum alloy and CFRTP with preset aluminum alloy sheet is proposed. In this process, the aluminum alloy sheet is preset between the carbon cloth and the PEEK, then compression molding is implemented to form the CFRTP containing the aluminum alloy sheet. The laser joining of CFRTP and aluminum alloy consists of two joining areas. The two joining areas are CFRTP-Al lap area and preset Al sheet-Al lap area, respectively.

Through the collective effect of the strength of the two laps, the joint strength of the CFRTP and the aluminum alloy is considerably improved. This paper introduces the manufacturing process of CFRTP with preset aluminum alloy sheet, while the laser joining of CFRTP and the aluminum alloy is further investigated. The fiber laser beam is utilized to bonding the CFRTP and the aluminum alloy. And then the joint is tested for tensile strength. Microstructure and fracture morphology of joint is observed according to the Optical Microscope (OM) and Scanning Electron Microscope (SEM). Based on the results, the diffusion behavior and distribution characteristic of elements in the lap area between CFRTP and aluminum alloy are analyzed, and the fracture characteristics of the joint are elucidated. 


\section{Experimental Details}

\subsection{Materials and preparation methods}

The experimental materials present 6061 aluminum alloy and CFRTP. The size of the aluminum alloy is $100 \times 25 \times 2 \mathrm{~mm}^{3}$. The chemical composition of 6061 aluminum alloy is shown in Table 1. PEEK and carbon cloth are layered and stacked in the mold in sequence during the preparation of CFRTP, the size of PEEK and carbon cloth are both $140 \times 120 \times 0.2 \mathrm{~mm}^{3}$. After stacking 3 layers of PEEK and 2 layers of carbon cloth, 5 pieces of 6061 aluminum with a size of $50 \times 25 \times 0.8 \mathrm{~mm}^{3}$ is evenly placed on the edge of PEEK plates, and thereafter 3 layers of PEEK and 2 layers of carbon cloth are laid in a symmetrical structure, as illustrated in Fig. 1 (a). Then they are hot-pressed formed in a plate vulcanizing machine. The melting temperature and thermal decomposition temperatures of PEEK are $616 \mathrm{~K}$ and $793 \mathrm{~K}$, respectively [25-27]. The relevant parameters of compression molding are depicted in Table 2 . The hotpressed CFRTP is cut into 5 test pieces with a size of $120 \times 25 \times 2 \mathrm{~mm}^{3}$, and one end of the test piece with preset aluminum alloy sheet is polished to expose the aluminum alloy sheet part of the area of $20 \times 25$ $\mathrm{mm}^{2}$.

Table 1

Composition of 6061 aluminum alloy (mass fraction, wt\%)

\begin{tabular}{|lllllllll|}
\hline $\mathbf{M g}$ & $\mathrm{Si}$ & $\mathrm{Fe}$ & $\mathrm{Cu}$ & $\mathrm{Mn}$ & $\mathrm{Zn}$ & $\mathrm{Cr}$ & $\mathrm{Ti}$ & $\mathrm{Al}$ \\
\hline $0.8-1.2$ & $0.4-0.8$ & $\leq 0.7$ & $0.15-0.4$ & $\leq 0.7$ & $\leq 0.7$ & $0.04-0.35$ & $\leq 0.7$ & Bal. \\
\hline
\end{tabular}

Table 2

Compression molding related parameters

\begin{tabular}{|llll|}
\hline Heating temperature & Pressure & Heating time & Pressurized time \\
$/\left({ }^{\circ} \mathrm{C}\right)$ & $/(\mathrm{MPa})$ & $/(\mathrm{h})$ & $/(\mathrm{h})$ \\
\hline 390 & 5.5 & 2 & 2.5 \\
\hline
\end{tabular}

\subsection{Laser joining process}

Figure 2 demonstrates a schematic diagram of the lap structure, the three lap areas in the figure are marked as interface A, interface B and interface $C$, respectively. Figure 3 shows a schematic diagram of the laser joining process. The joining process is formed by two fiber laser beams. Firstly, the first laser beam is carried out to bonding aluminum alloy and preset aluminum alloy sheet. Then the lapping structure is turned over and clamped after finishing the first laser joining process, the second laser beam is carried out to bonding aluminum alloy and CFRTP. The first laser beam is used for the metal-to-metal lap joining, while the second laser beam is used for the heat conduction joining between the metal and CFRTP. The required heat input of the two differs greatly, which results in a large difference in the parameters of the two lasers. The relevant parameters of the two processes are listed in Table 3 after various parameter attempts and optimizations in the early stage. The aluminum alloy receives the heat of 
the second laser beam and conducts the heat to the CFRTP to melt the resin at the interface. Under the clamping pressure, the resin cools and solidifies to achieve the joining between the aluminum alloy and CFRTP.

Table 3

Laser joining related parameters

\begin{tabular}{|lllll|}
\hline Joining process & $\begin{array}{l}\text { Laser power } \\
\text { /(W) }\end{array}$ & $\begin{array}{l}\text { scanning speed } \\
/\left(\mathrm{m} \cdot \mathrm{min}^{-1}\right)\end{array}$ & $\begin{array}{l}\text { Defocus } \\
/(\mathrm{mm})\end{array}$ & $\begin{array}{l}\text { Shielding gas flow } \\
/\left(\mathrm{L} \cdot \mathrm{min}^{-1}\right)\end{array}$ \\
\hline $\begin{array}{l}\text { The first } \\
\text { joining process }\end{array}$ & 2400 & 2.0 & -1 & 15 \\
\cline { 1 - 2 } \begin{tabular}{l} 
The second joining process \\
\hline
\end{tabular} & 300 & 1.8 & & +15 \\
\hline
\end{tabular}

\subsection{Evaluations of the microstructure and mechanical properties}

After the joining process is completed, a tensile specimen and a metallographic specimen are conducted separately. Keller's reagent $\left(2.5 \% \mathrm{HNO}_{3}+1.5 \% \mathrm{HCl}+1 \% \mathrm{HF}+95 \% \mathrm{H}_{2} \mathrm{O}\right)$ is adopted to polish and etch the metallographic sample. The interface morphology of the joint is observed with an OM and SEM. In order to evaluate the mechanical properties of the joints, a universal mechanical property testing machine is employed to test the tensile properties of the specimens at room temperature with a tensile speed of 1 $\mathrm{mm} / \mathrm{min}$. In addition, the fracture morphology of the specimen is observed and analyzed by SEM, the element distribution of the joint interface is investigated by Energy Disperse Spectroscopy (EDS), and the element diffusion behavior of the interface is further elucidated.

\section{Results And Discussion}

\subsection{Appearances of the joint}

Two laser beams are applied to bonding both sides of the sample, and a sample of aluminum alloy and CFRTP overlap is obtained. The tensile test is performed after the two ends of the tensile specimen are bonded with gaskets of equal thickness. The purpose of bonding the gaskets is to eliminate the torque during the tensile test. Figure 4 depicts the schematic diagram of the tensile sample and the sample fracture after the tensile test. The fracture position of the sample is near the $0.8 \mathrm{~mm}$ thick aluminum alloy weld seam. Later, in order to analyze the element diffusion and microscopic morphology of the lap interface of the sample, OM and SEM are adopted to observe and analyze the metallographic sample.

\subsection{Joint cross-section analysis}


The metallographic sample was observed through $\mathrm{OM}$, and the cross-sectional morphology of the joint sample was displayed in Fig. 5. The 6061 aluminum alloy base metal is mainly a-Al phase, which is flat fibrous, and a small amount of $\beta-\mathrm{Mg}_{2} \mathrm{Si}$ phase is evenly distributed in a phase. The laser joining process is a complicated thermal process, and the microstructure of the joint will change with various thermal effects. According to the boundary conditions of structural undercooling [28], the direct contact between the microstructure near the fusion line of the joint and the no molten metal causes a great degree of undercooling. The fusion line forms a certain temperature gradient along the center of the weld seam to form elongated columnar crystals. In the center of the weld seam, an equiaxed crystal is formed due to the undercooling. In addition, dense pores are found near the fusion line. Under the action of external force, these pores will gradually expand and become the weakest point of the bearing capacity of the joint.

EDS detection is performed at the place where the interface is tightly connected, the line scan component analysis is conducted according to the scanning path in Fig. $6(\mathrm{a})$, and the component distribution detection is implemented at point $A$, which is $2 \mu \mathrm{m}$ away from the interface $A$. The detection results are exhibited in Fig. 6 (b, d). The two ends of the scanning path are aluminum alloy and CFRTP, respectively. The main component of the aluminum alloy side is $\mathrm{Al}$ element, and the content of $\mathrm{C}$ element is almost 0 . Similarly, the main element on the CFRTP side is C element, and the Al element is almost 0 , but a very thin reaction layer can be observed at the interface $A$. Through the analysis of the composition at point $A$, the main component is $\mathrm{C}$ element with a mass fraction of $86.85 \%$, and the remaining components are $\mathrm{Al}$ element with a mass fraction of $4.67 \%$. It indicated that the Al element within the aluminum alloy diffuses into the CFRTP side with the combination effect of laser thermal influence and the clamping pressure. Through the EDS surface scan composition distribution in Fig. 6(c), the diffusion of elements in the reaction layer at the interface can be seen more intuitively. The diffusion of elements indicates that chemical joining is produced at the joining interface, and the joining of chemical bonds can effectively improve the strength of the interface.

In addition, the hot-pressed forming interface between preset aluminum alloy sheet and CFRTP has also been analyzed. Figure 7 shows the morphology of the interface $B$ and the line-scan composition analysis of EDS. There are almost no defects such as bubbles and unfusion at the interface through observation and analysis. Long-term hot pressing is conducive to the full diffusion of bubbles, and the interface is heated evenly so that all parts of the interface joining can be efficiently connected, the interface is more tightly connected with long-term pressurization. According to the line scan results in Fig. 7 (b), compared with Fig. 6 (b), the interface reaction layer is larger. On the CFRTP side, a point B is selected, which is also $2 \mu \mathrm{m}$ away from the interface $B$. Then the composition analysis of point $B$ indicates that the main element at this point is the $C$ element, and the content is $83.54 \%$, and the content of $\mathrm{Al}$ element reaches $9.19 \%$, which is higher than the content of $\mathrm{Al}$ at point $\mathrm{A}$. This implies that under the effect of long-term hot pressing, the Al element in the aluminum alloy and the $\mathrm{C}$ element in the CFRTP have been fully diffused, and the chemical joining strength is higher. Therefore, the interface between preset aluminum alloy sheet 
and CFRTP forms a high-strength joining with high chemical joining strength and tighter mechanical engagement force.

\subsection{Joint fracture surface analysis}

In order to further explore the tensile fracture characteristics of the sample, the fracture of the sample is observed and analyzed by SEM. The sample fractured in two places, one is the fracture of the lap interface between the CFRTP and the aluminum alloy, and the other is the fracture at the lap of preset aluminum alloy sheet and aluminum alloy. Firstly, in order to analyze the failure mode of the CFRTP and aluminum alloy lap interface, the morphology of the interface was studied. According to the morphology of the CFRTP side of the lap interface shown in Fig. 8, a lot of torn resin and exposed carbon fibers can be observed. In the lap laser bonding process of CFRTP and aluminum alloy, the thermal effect of the laser melts the surface resin of CFRTP and fills it into the rough aluminum alloy surface, then the resin is cooled to form a joint. During the stretching process, due to the high bonding force between aluminum alloy and some resins, the resin on the surface of the CFRTP is pulled out under the under the action of moving aluminum alloy, while some carbon fibers covered by the resin are exposed. Through the EDS surface scan composition analysis of Fig. 8 (b), it is found that in addition to the $C$ element, there is a sparse distribution of Al elements on the surface. Due to the laser thermal effect, only a small amount of Al element diffuses, but this also reflects the unevenness of the laser thermal effect, and the diffusion of interface elements is not sufficient, which limits improvement of the joining strength. The EDS surface scan results in Fig. 8 (d) also confirm the above-mentioned cross-sectional element diffusion results.

On the other hand, a small amount of residual resin can be found by observing and analyzing the morphology of the aluminum alloy side of the interface. It indicates that the joining strength between the aluminum alloy and the resin in this area is higher than the strength of the resin itself in CFRTP. During the stretching process, the resin is torn from the CFRTP and remains on the surface of the aluminum alloy. However, Large amount of areas without residual resin are still observed on the surface of the aluminum alloy, indicating that a lot of resin at the interface is utterly peeled off from the surface of the aluminum alloy during the stretching process. It can be clearly seen from the EDS surface scan composition analysis results of part of the aluminum alloy surface in Fig. 9(d) that the yellow in the figure represents the $\mathrm{Al}$ element, while the red representing the $\mathrm{C}$ element is scattered on the surface of the aluminum alloy, and the red spots represent resin remaining on the surface of aluminum alloy. Therefore, it can be judged that the failure mode of the sample joint is a mixed fracture, which includes cohesive fracture and adhesive fracture. The three fracture modes of the joint are shown in Fig. 10. However, owing to only a small amount of resin is found on the surface of aluminum alloy, the failure mode is mixed fracture with adhesive fracture as the main component. Among them, cohesive fracture is caused by the resin tearing due to the interface bonding force between the resin and the aluminum alloy is greater than the ultimate bearing capacity of the resin itself, and the interface failure is caused by the weaker bonding force between the resin and the aluminum alloy compared with the ultimate bearing capacity of the resin itself, so that resin is completely peeled from the surface of the aluminum alloy. In the stretching process, the stretching force causes a small amount of resin to plastically deform, but 
most of the interface area is the direct peeling of aluminum alloy and CFRTP. When a certain tensile load is reached, the joint fails with almost no plastic deformation, indicating that the lap interface appears as brittle fracture.

The lap fracture of preset aluminum alloy sheet and aluminum alloy is analyzed and observed. The microscopic morphology of the aluminum alloy fracture is indicated in Fig. 11. It can be seen from Fig. 11(a) that there are a few pores in the fracture section, and these pores are generally distributed near the fusion line. When the joint is under force, the pores will primarily become the source of crack propagation, reducing the mechanical properties of the joint. It can be seen from Fig. 11(b) that the elliptical dimples can be clearly seen. These dimples have large differences in size and present obvious unevenness, indicating that the fracture mode of the sample is a ductile fracture. For ductile fracture, the fracture process is usually divided into three stages: micropore formation, expansion and aggregation. Since the pores formed by laser joining will gradually expand under external force, these expanded gaps will extend along the direction of the aluminum alloy dislocation slip. In addition, the aluminum alloy has a face-centered cubic structure with numerous slip systems and extremely fast gap expansion. After reaching a certain degree of plastic deformation, the joint will eventually fracture at the place with the weakest bearing capacity.

\subsection{Joint fracture characteristics}

The force-displacement curve of the joint after the tensile test is demonstrated in Fig. 12. The maximum tensile load of the joint is $4264 \mathrm{~N}$. Based on the analysis results of the fracture surface above, the stretching process can be roughly divided into three stages: The first stage is two laps work together until the CFRTP and aluminum alloy lap area fails. The slope of the curve at this stage is larger, and the size of the slope is related to the strength of the joint. Under the same tensile displacement, the greater the slope, the higher the tensile strength; In the second stage, the lap area between CFRTP and aluminum alloy has failed, and the lap between preset aluminum alloy sheet and aluminum alloy works alone, and the plastic deformation of the aluminum alloy causes tortuous changes in the tensile curve; The third stage is the failure stage. The aluminum alloy fractures after a certain amount of plastic deformation. Figure 13 shows the fracture characteristics of the joint. When the tensile force reaches a certain load, due to the low resin content on the surface of CFRTP, the lapped area between CFRTP and aluminum alloy fails when almost no plastic deformation occurs, showing brittle fracture. The strength of the lap area of aluminum alloy is larger than that of CFRTP and aluminum alloy. When the lap area of CFRTP and aluminum alloy fails, plastic deformation occurs near the fusion area of aluminum alloy lap welding. In the process of plastic deformation of aluminum alloy, the pores near the fusion line are expanded by an external force. When the load reaches the limit, the aluminum alloy fails and fractures.

\section{Conclusion}

In order to improve the joining strength between CFRTP and aluminum alloy, a new laser joining process of CFRTP with preset aluminum alloy sheet and aluminum alloy is proposed. The maximum tensile load 
of the joint by this method can reach $4264 \mathrm{~N}$. The diffusion of elements in the joint and the joining characteristics of the joint are discussed. The results indicate that there is the element diffusion at the interface of CFRTP-Al and the interface of preset Al sheet-CFRTP. And due to the hot-pressed effect, the element diffusion range between preset aluminum alloy sheet and CFRTP is more appreciable. The failure mode of the lap structure between CFRTP and aluminum alloy is a mixed failure dominated by adhesive failure. The fracture location of the lap structure between preset aluminum alloy sheet and aluminum alloy occurred near the weld seam fusion line, and the fracture behavior is ductile fracture. The collective effect of the interface of CFRTP-Al and the interface of preset Al sheet-Al increases the strength of the joint. And during the stretching process, the interface between CFRTP and aluminum alloy undergoes failure, then the aluminum alloy undergoes plastic deformation until the joint fails.

\section{Declarations}

\section{Funding}

No funding was received for conducting this study.

\section{Conflicts of interest}

The authors declare no competing interests.

\section{Availability of data and material}

Data and materials are available.

\section{Code availability}

Not applicable.

\section{Ethics approval}

Not applicable.

\section{Consent to participate}

Not applicable.

\section{Consent for publication}

All authors have read and agreed to the published version of the manuscript.

\section{Authors' contributions}

The materials preparation was conducted by Jiebang Luo. The welding experiment was conducted by Feiyun Wang. Data processing and manuscript preparation were led by Jiebang Luo with contributions 
from all authors.

\section{References}

1. Kim DW, Jin CK, Lee MS et al (2020) Investigation of optimal lamination condition of CFRTP by compression molding method and a comparison of mechanical properties with CFRTS, Adv Mech Eng. 12(12)

2. Roberts T (2007) Rapid growth forecast for carbon fibre market. Reinforced Plastics 51(2):10-13

3. Edwards KL (1998) An overview of the technology of fibre-reinforced plastics for design purposes. Mater Design 19(1-2):1-10

4. Williams JC, Strake EA Jr (2003) Progress in structural materials for aerospace systems. Acta Mater 51(19):5775-5799

5. Tong D, Yi Y, He H et al (2020) Manufacturing large 2A14 aluminium alloy cylinders by a warm rolling technology. Mater Sci Tech-lond. 1-13

6. Fang $X$, Zhang $L$, Chen $G$ et al (2020) Microstructure evolution of wire-arc additively manufactured 2319 aluminum alloy with interlayer hammering. Mater Sci Eng A. 140168

7. Molitor P, Barron V, Young T (2001) Surface treatment of titanium for adhesive bonding to polymer composites: a review. Int J Adhes Adhes 21(2):129-136

8. Lambiase F, llio AD (2015) Mechanical clinching of metal-polymer joints. J Mater Process Tech 215:12-19

9. Jiao J, Jia S, Xu Z (2019) Laser direct joining of CFRTP and aluminium alloy with a hybrid surface pre-treating method. Compos Part B-Eng. 173(Sep.15):106911.1-106911.7

10. Gao Q, Li Y, Wang H et al (2019) Effect of Scanning Speed with UV Laser Cleaning on Adhesive Bonding Tensile Properties of CFRP. Appl Compos Mater 26(3):1-13

11. Salamati M, Soltanpour M, Fazli A et al (2019) Processing and tooling considerations in joining by forming technologies; part A-mechanical joining. Int J Adv Manuf Technol 101(1-4):261-315

12. Sheng L, Jiao J, Du B et al (2018) Influence of Processing Parameters on Laser Direct Joining of CFRTP and Stainless Steel. Adv Mater Sci Eng. 2018: 1-15

13. Zhang Z, Shan J, Tan X et al (2016) Improvement of the laser joining of CFRP and aluminum via laser pre-treatment. Int J Adv Manuf Technol 90:3465-3472

14. Roesner A, Scheik S, Olowinsky A et al (2011) Laser assisted joining of plastic metal hybrids. Physics Procedia 12:370-377

15. Jung KW (2013) Laser direct joining of carbon fiber reinforced plastic tozinc-coated steel. Mater Design 47:179-188

16. Jung KW (2013) Laser direct joining of carbon fibre reinforced plastic to stainless steel. Sci Technol Weld Joi 16:676-680 
17. Jung KW (2013) Laser direct joining of carbon fiber reinforced plastic to aluminum alloy. J Laser Appl 47:179-188

18. Sheng L, Jiao J, Lai C (2018) Assessment of the microstructure and mechanical properties of a laserjoined carbon fiber-reinforced thermosetting plastic and stainless steel. Strength Mater 50:752-763

19. Zhang X, Chen W, Bao G (2003) Improvement of Weld Quality with Beam-Weaving Laser Welding (1709). 22nd International Congress on Applications of Lasers \& Electro-Optics (ICALEO 2003)

20. Huang C, Wang X, Wu Y et al (2014) Experimental Study of Laser Direct Joining of Metal and Carbon Fiber Reinforced Nylon. Key Engineering Materials 620:42-48

21. Lambiase F, Genna S (2018) Experimental analysis of Laser assisted joining of Al-Mg aluminium alloy with Polyetheretherketone (PEEK). Int J Adhes Adhes

22. Zhou Z, Tan X, Jing Z et al (2018) Suppression of shrinkage porosity in laser-joining of CFRP and steel using a laser surface modification process "Surfi-Sculpt". Int J Adhes Adhes 85:184-192

23. Zhang Z, Shan J, Tan X (2017) Evaluation of the CFRP grafting and its influence on the laser joining CFRP to aluminum alloy. J Adhes Sci Technol 32(4):1-17

24. Zhang Z, Shan J, Tan X (2016) Effect of anodizing pretreatment on laser joining CFRP to aluminum alloy A6061. Int J Adhes Adhes. 70

25. Yan M, Tian X, Peng G et al (2018) High temperature rheological behavior and sintering kinetics of CF/PEEK composites during selective laser sintering. Compos Sci Technol

26. Li Y, Bu H, Yang H et al (2020) Effect of laser heat input on the interface morphology during laser joining of CFRTP and 6061 aluminum alloy. J Mater Process Technol 50(8):366-379

27. Bu H, Li Y, Yang H, Wang L, Zhan X (2020) Investigation of laser joining process of CFRTP and aluminum alloy. Mater Manuf Process 35:1251-1258

28. Zhan X, Bu H, Gao Q et al (2019) Temperature field simulation and grain morphology on laser welding-brazing between Ti-6Al-4V and 1050 aluminum alloy. Mater Res Express. 6(5)

\section{Figures}




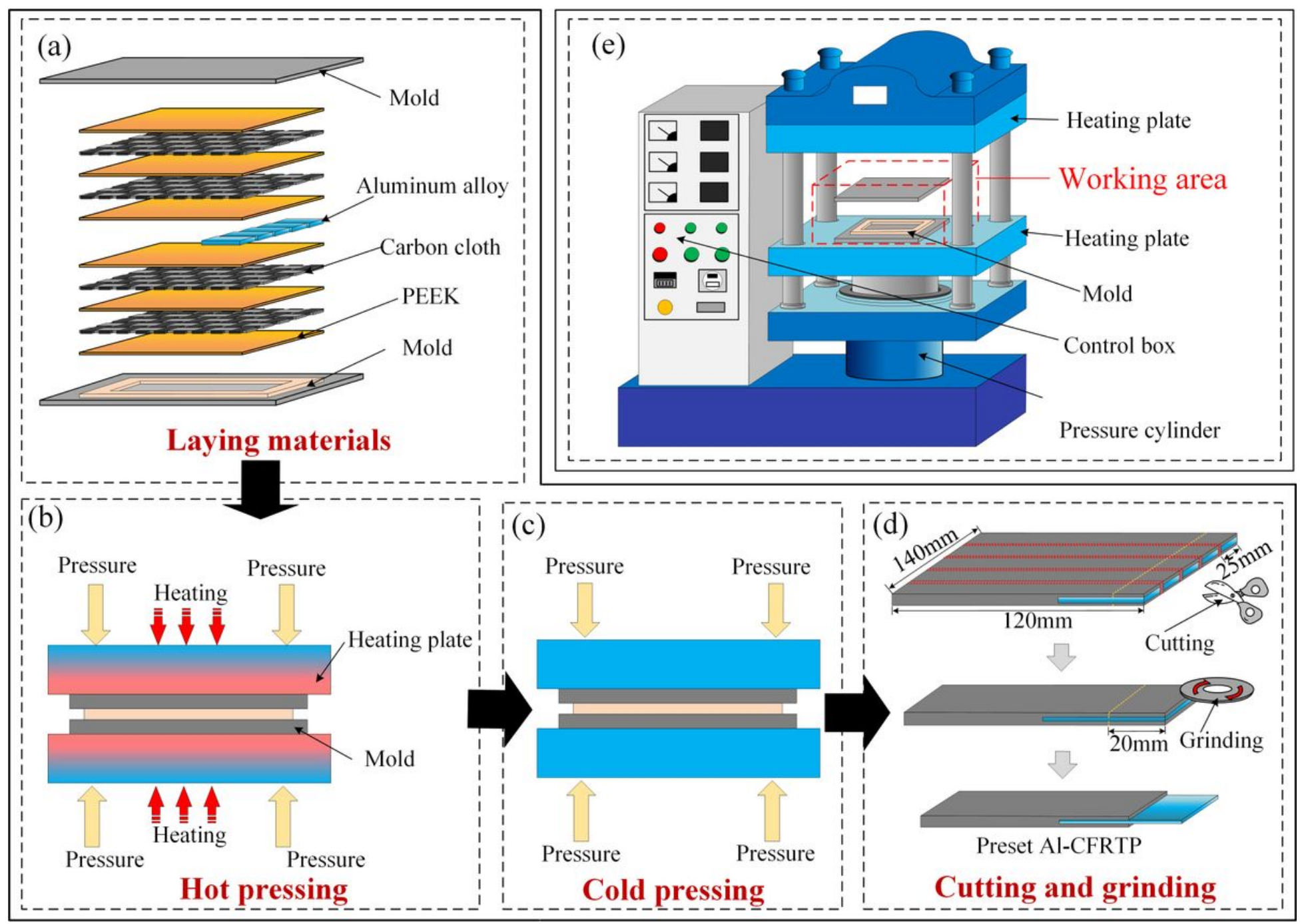

\section{Figure 1}

(a-d) CFRTP with preset aluminum alloy sheet preparation flow chart(e) Flat vulcanizing machine 


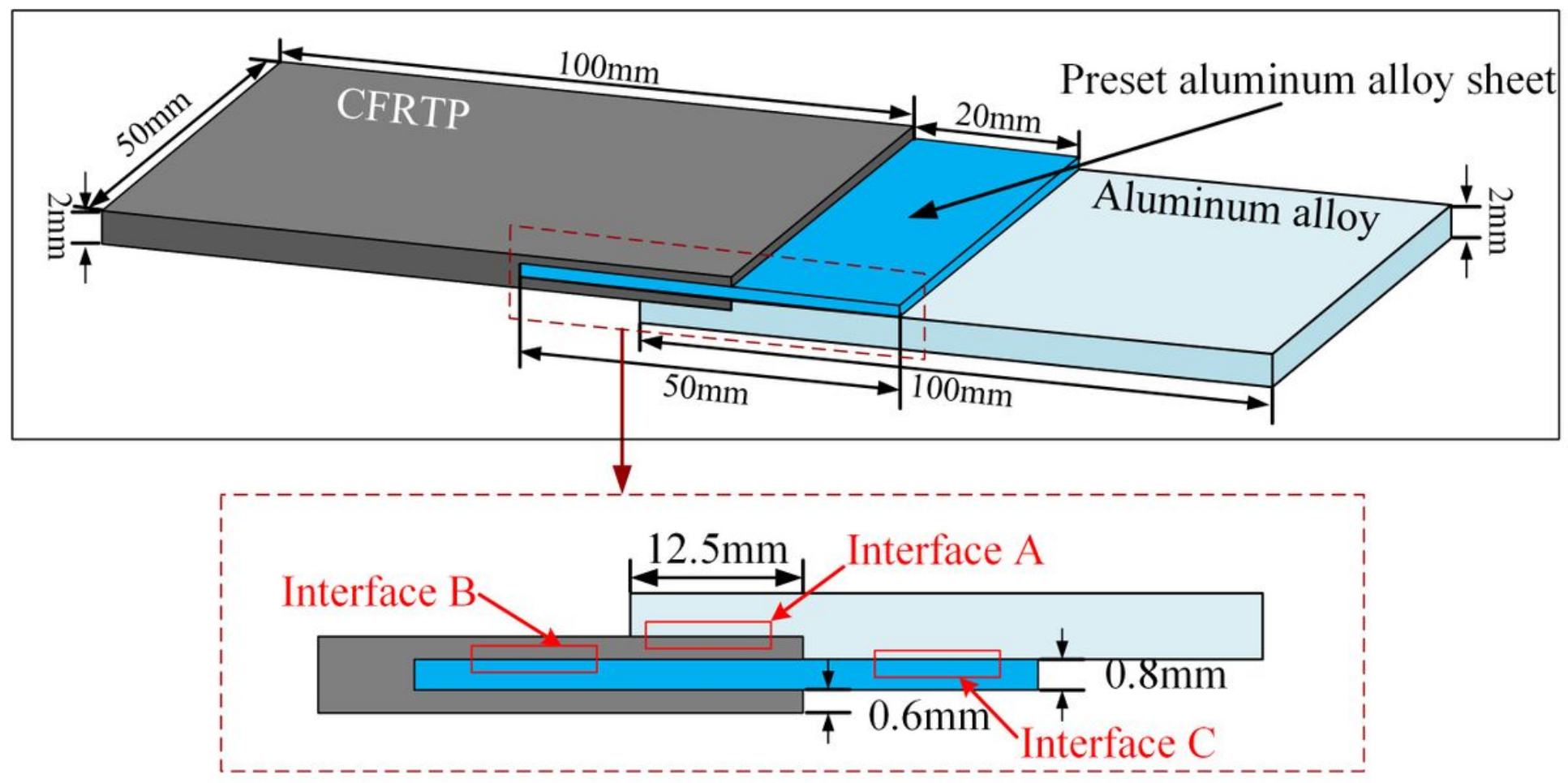

Figure 2

Schematic diagram of the lapping structure

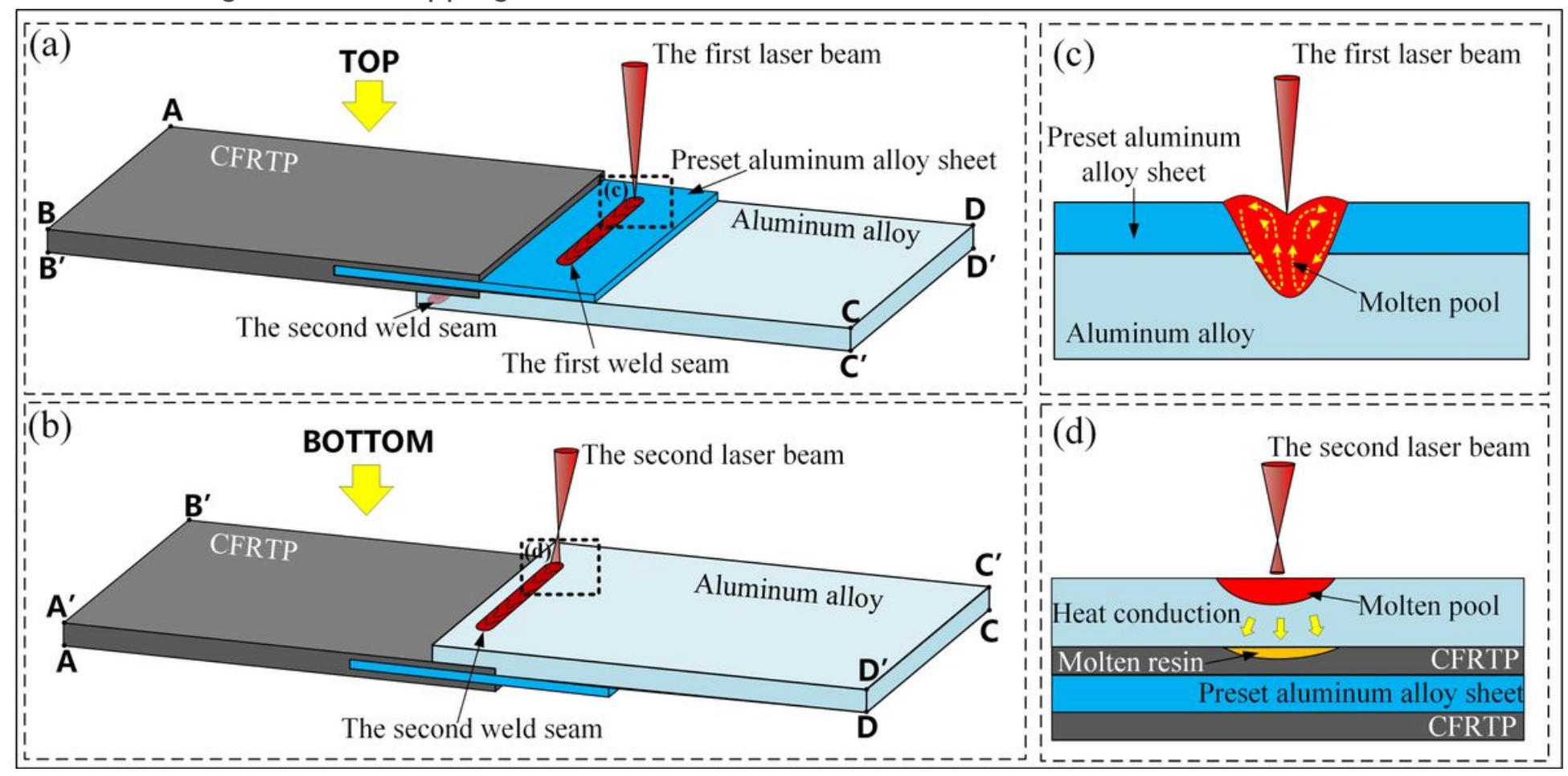

Figure 3

Schematic diagram of laser joining. (a) The first joining process(b) The second joining process(c) Crosssection of the specimen during the first joining process (d) Cross-section of the specimen during the second joining process 

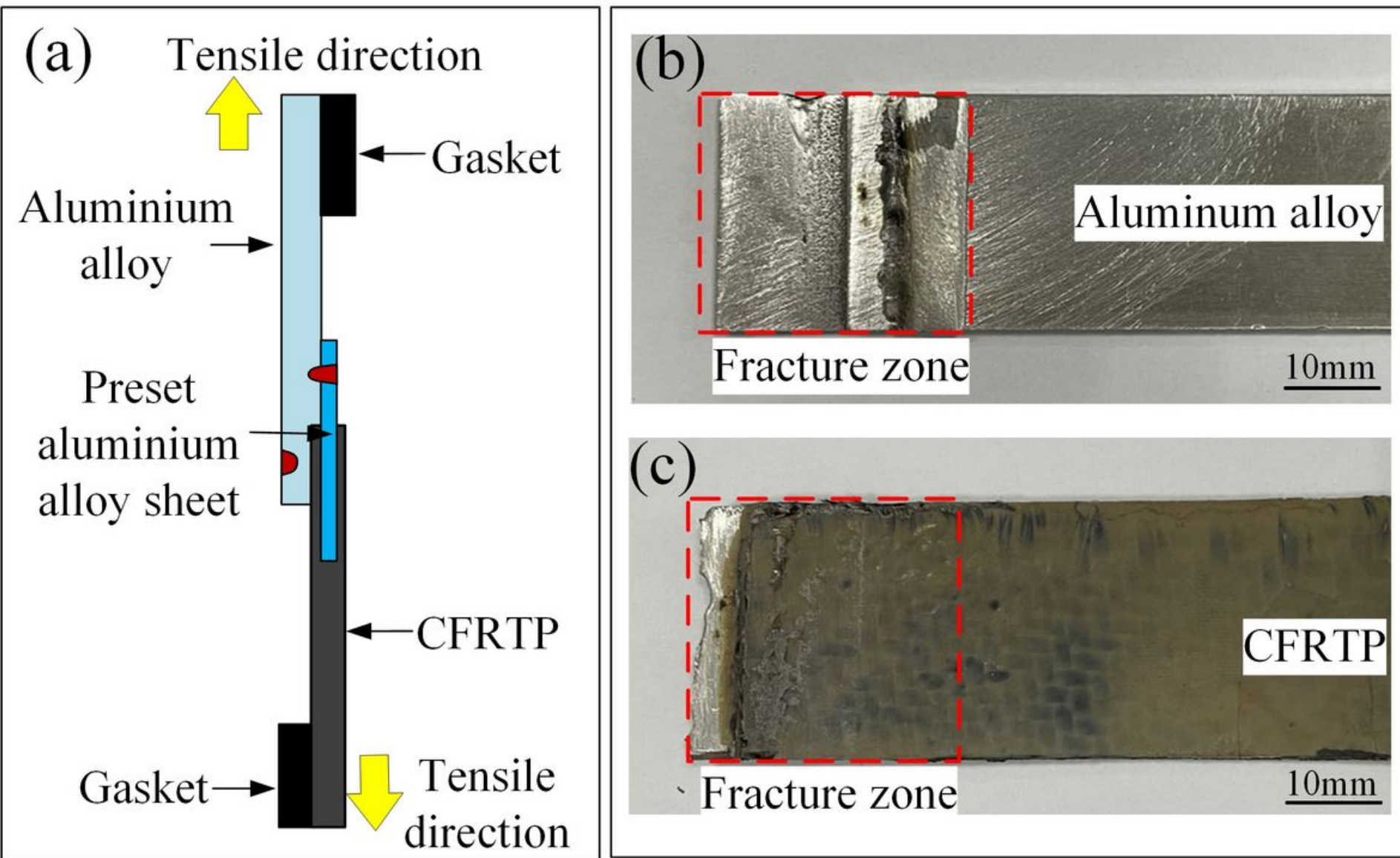

(c)

CFRTP

- Fracture zone

$\underline{10 \mathrm{~mm}}$

\section{Figure 4}

Tensile fracture morphology of sample (a) Schematic diagram of sample tensile test. (b) the aluminum alloy part of the sample after the tensile test. (c) CFRTP part of the sample after the tensile test.

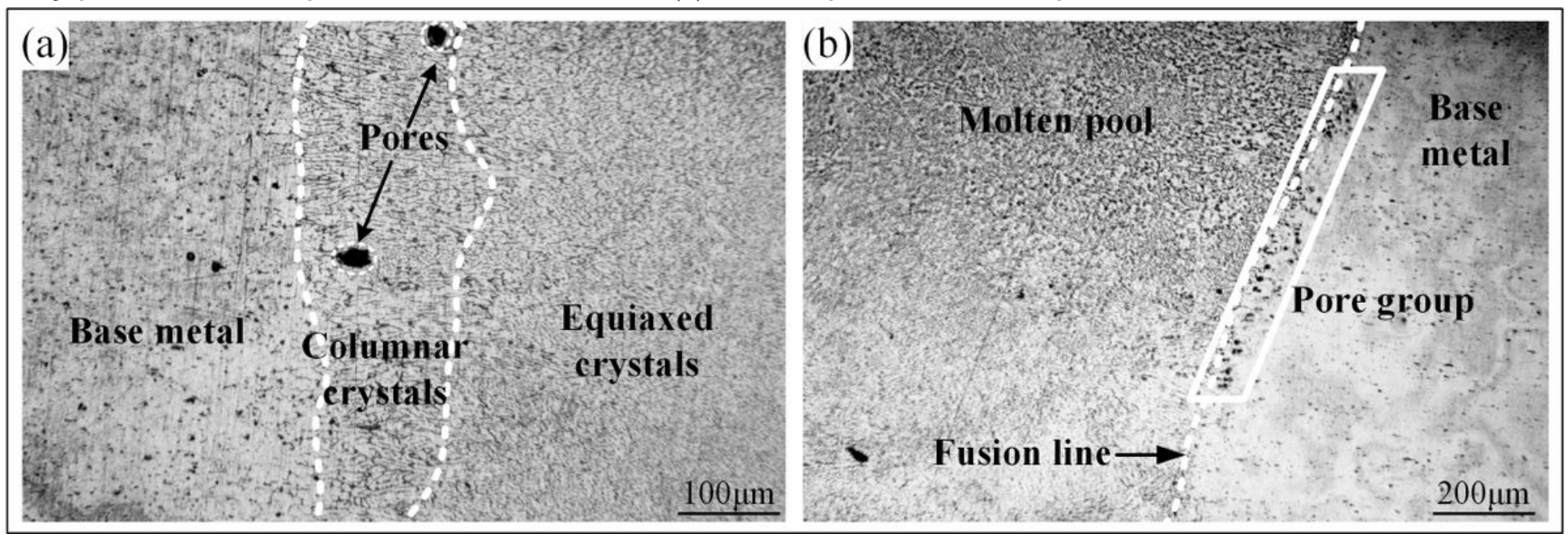

Figure 5

The microstructure of aluminum alloy lap laser welding. (a) $100 \mathrm{X}$. (b) $50 \mathrm{X}$. 


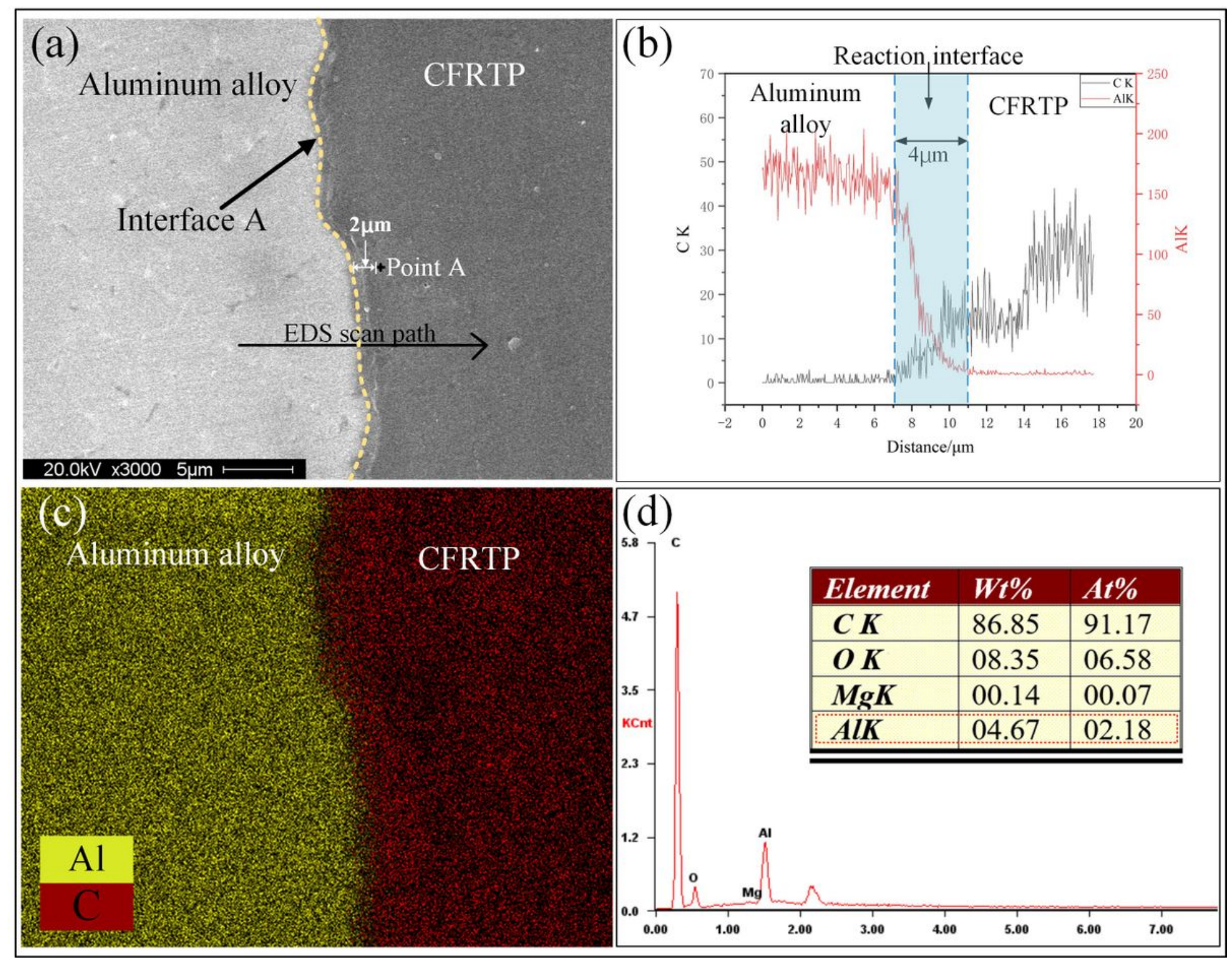

Figure 6

Morphology and element distribution of the lapped cross-section of CFRTP and aluminum alloy. (a) Morphology of cross-section of CFRTP and aluminum alloy. (b) EDS test result of scanning track in (a). (c) EDS surface scan result of (a). (d) Point A's composition test result 


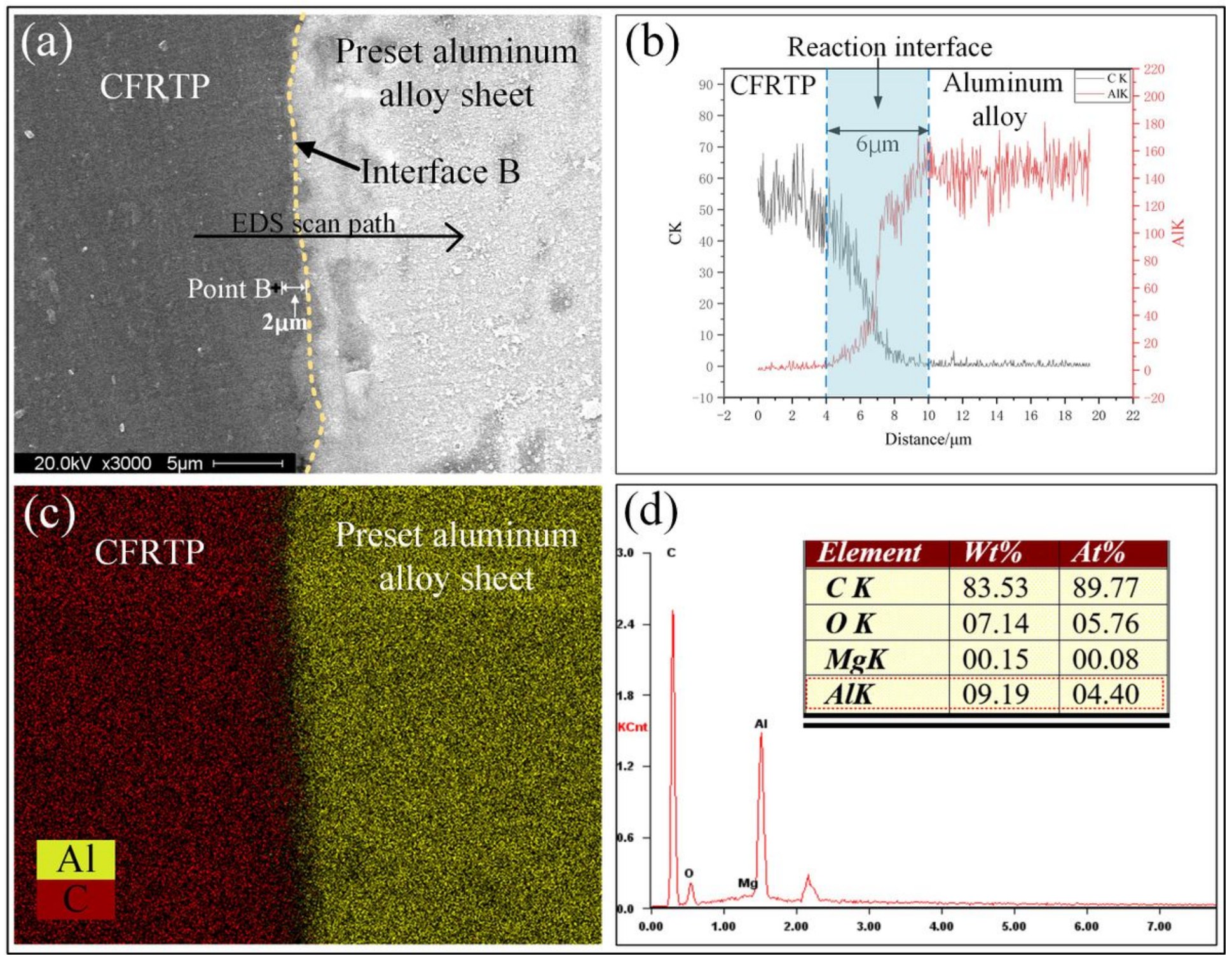

Figure 7

Morphology and element distribution of the lapped cross-section of CFRTP and preset aluminum alloy sheet. (a) Morphology of cross-section of CFRTP and preset aluminum alloy sheet. (b) EDS test result of scanning track in (a). (c) EDS surface scan result of (a). (d) Point B's composition test result 


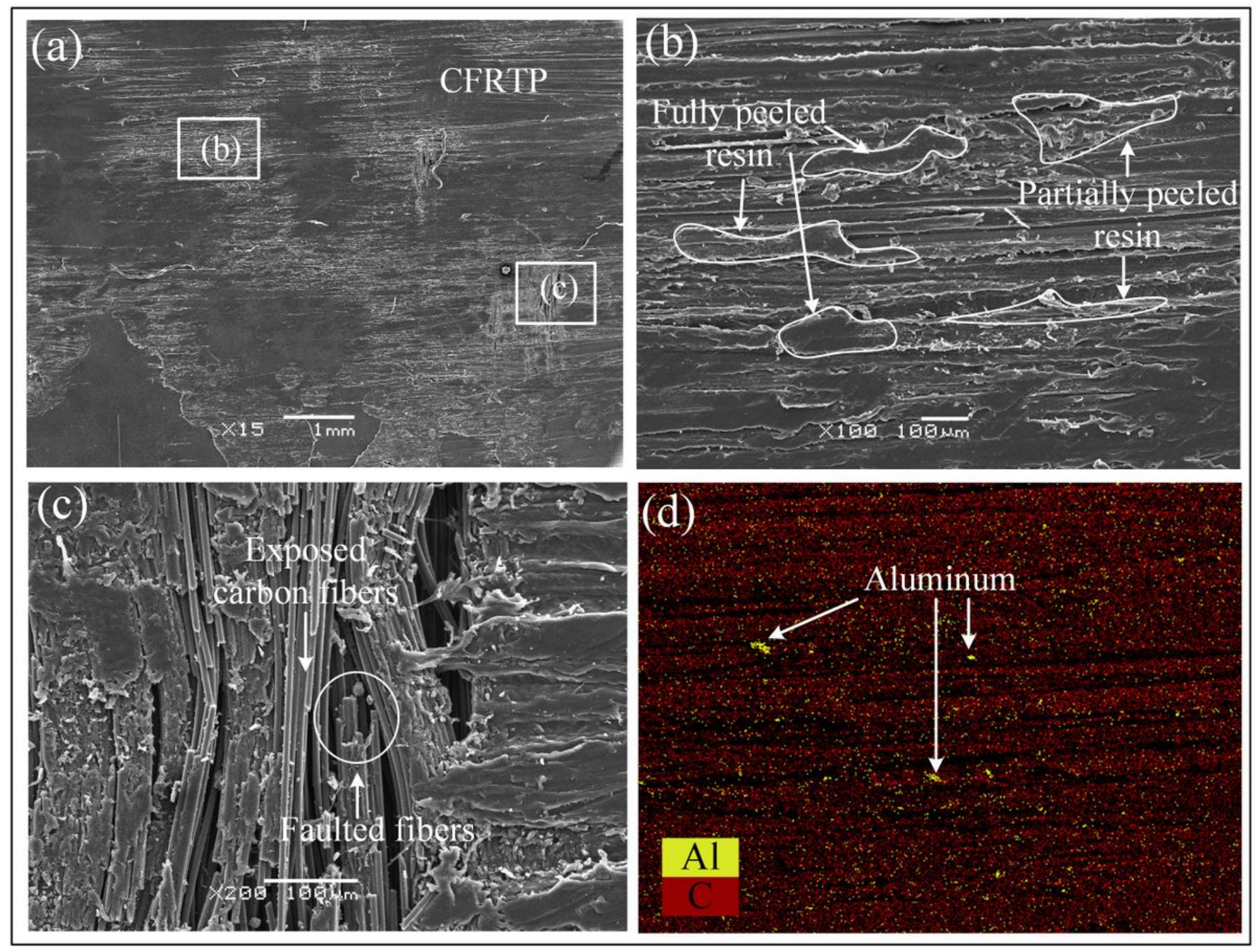

\section{Figure 8}

Morphology and element distribution on the CFRTP side of the interface between CFRTP and aluminum alloy. (a) Morphology on the CFRTP side of the interface between CFRTP and aluminum alloy. (b, c) Partially enlarged view of morphology. (d) Morphology EDS surface scan test results 


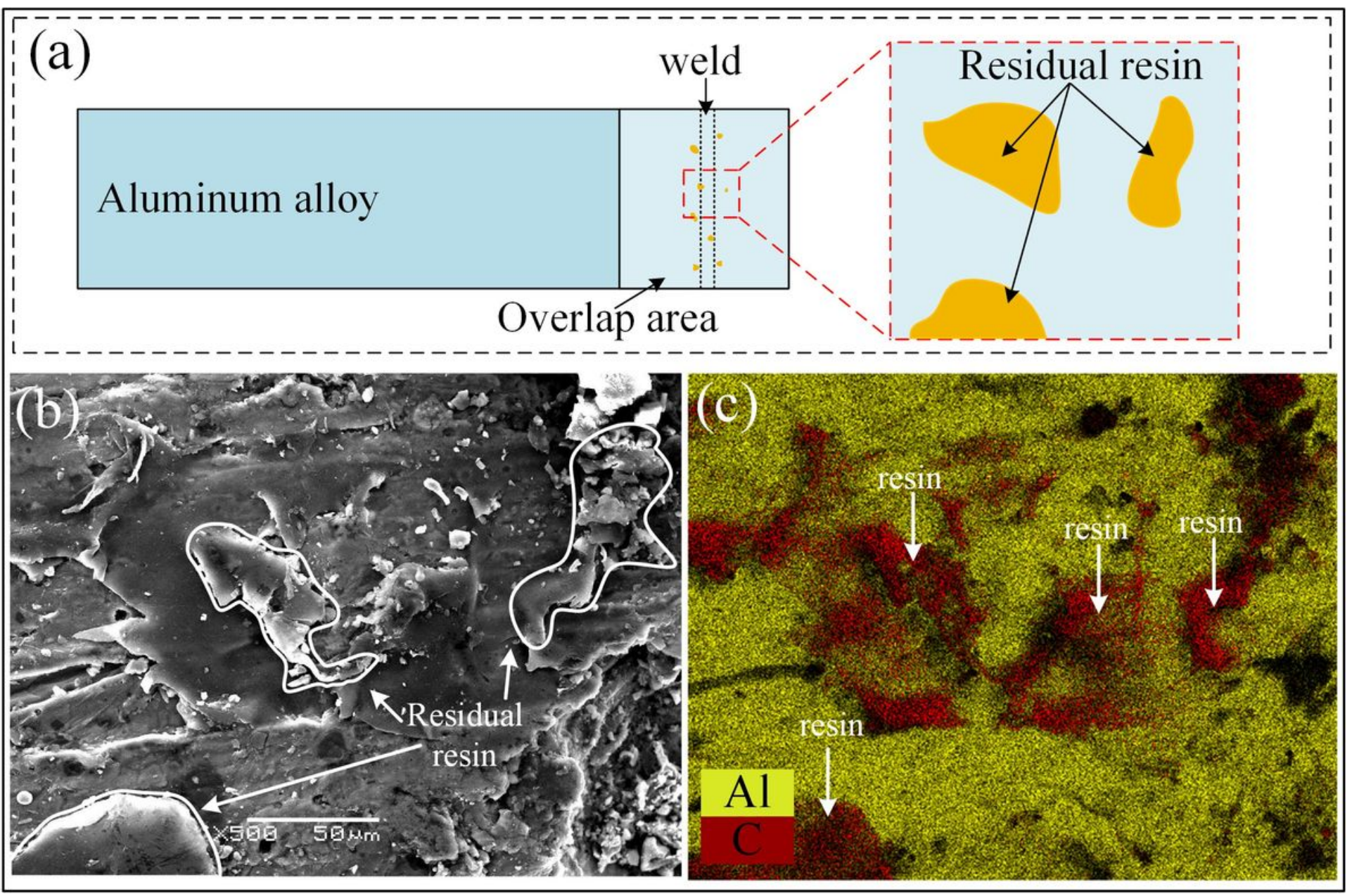

Figure 9

Morphology and element distribution on the aluminum alloy side of the interface between CFRTP and aluminum alloy. (a) Schematic diagram of residual resin on aluminum alloy surface. (b) Partially enlarged view of morphology. (c) Morphology EDS surface scan test results.

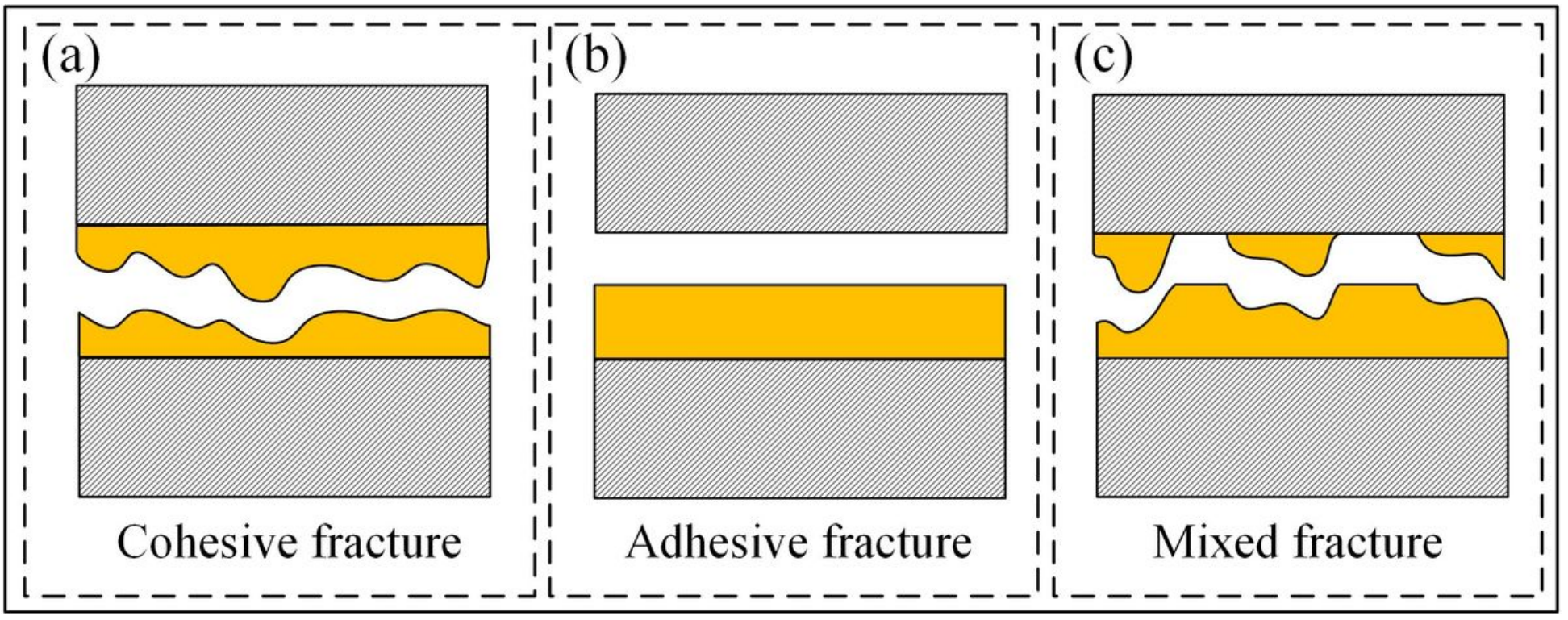

Figure 10 
Lap joint fracture mode. (a) Cohesive fracture. (b) Adhesive fracture (c) Mixed fracture.

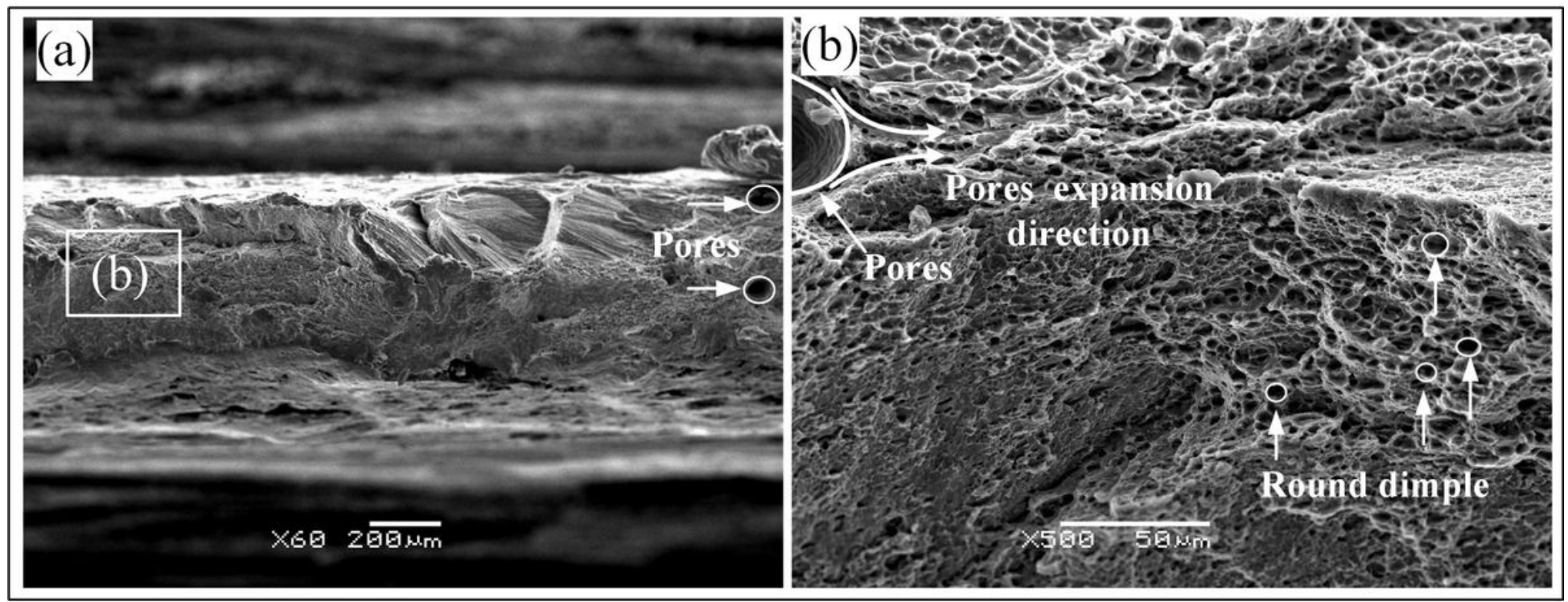

\section{Figure 11}

Fracture surface of aluminum alloy lap structure. (a) Aluminum alloy fracture surface morphology. (b) Partially enlarged view. 


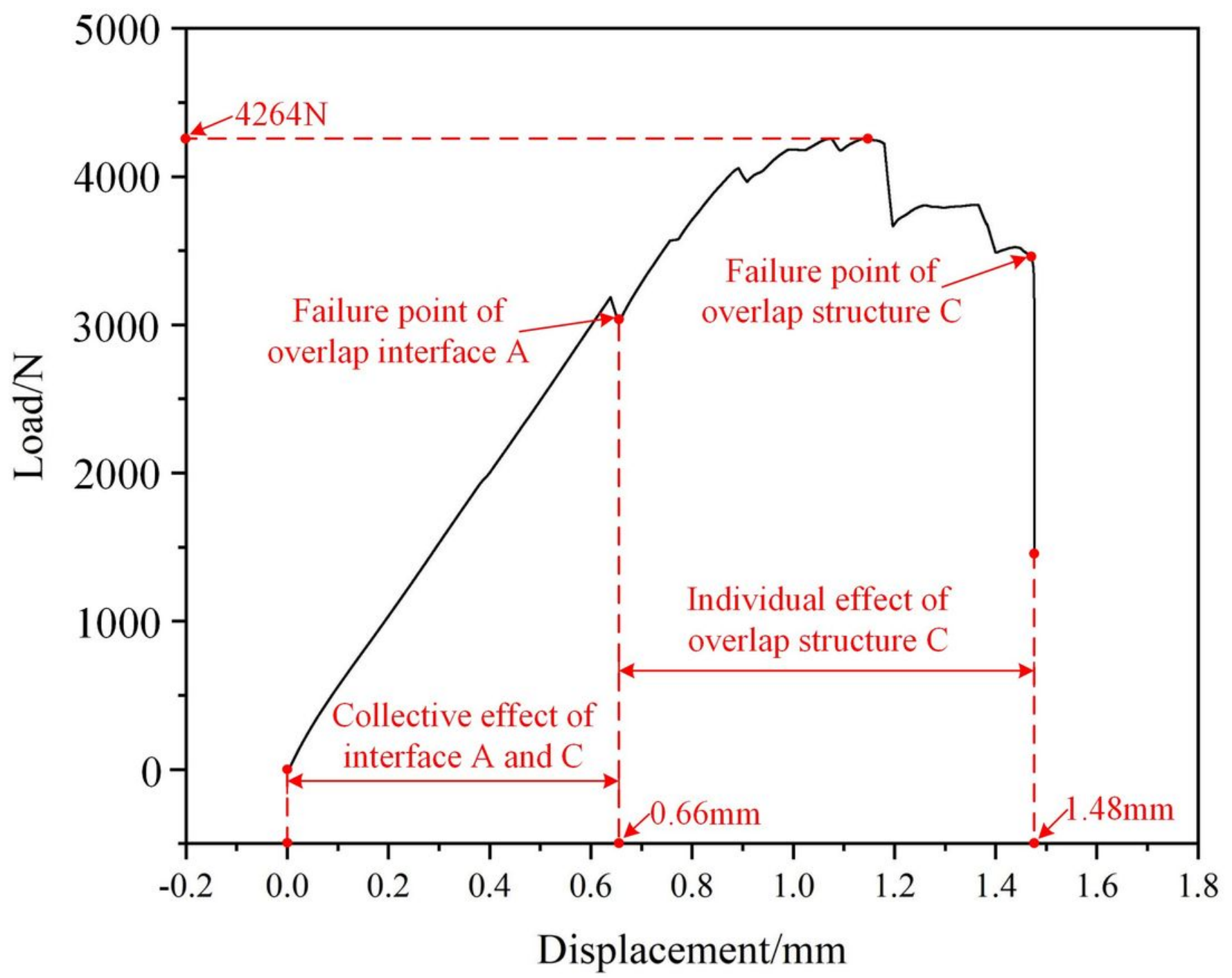

Figure 12

Force-displacement curve of specimen tensile test 


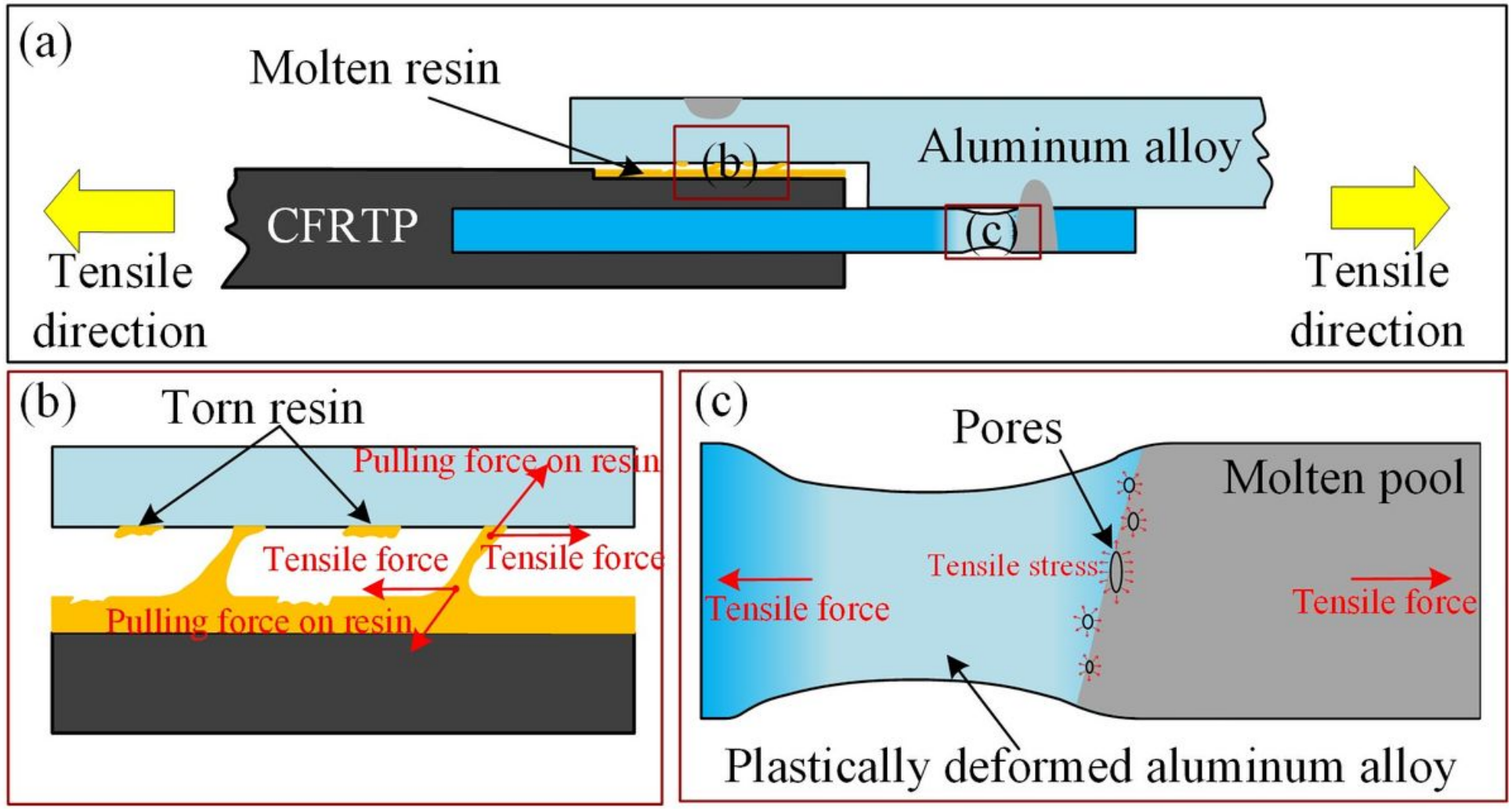

Figure 13

Schematic diagram of joint fracture process. (a) Joint stretching process. (b, c) Partial enlarged view. 